\title{
18F-fluorodeoxyglucose positron emission tomography- computed tomography as a screening tool for second primary cancers in cancer patients
}

\author{
Yang Liu ${ }^{1, *}$, Jie $\mathrm{Ma}^{2, *}$ and Yingxin Liu ${ }^{1}$ \\ ${ }^{1}$ Department of Radiation Oncology, Cancer Hospital of Guangxi Medical University, Nanning, People's Republic of China \\ ${ }^{2}$ Department of Radiology, Cancer Hospital of Guangxi Medical University, Nanning, People's Republic of China \\ *The co-first authors \\ Correspondence to: Yingxin Liv, email: liuyingxinrt@sina.com \\ Keywords: second primary cancers, PET-CT, staging \\ Received: August 03, $2017 \quad$ Accepted: August 18, $2017 \quad$ Published: September 30, 2017 \\ Copyright: Liu et al. This is an open-access article distributed under the terms of the Creative Commons Attribution License 3.0 \\ (CC BY 3.0), which permits unrestricted use, distribution, and reproduction in any medium, provided the original author and source \\ are credited.
}

\section{ABSTRACT}

Background: We performed a meta-analysis to evaluate the value of ${ }^{18} \mathrm{~F}$-fluorodeoxyglucose positron emission tomography-computed tomography ( ${ }^{18} \mathrm{FDG}$ PET-CT) for the detection of second primary cancers in cancer patients.

Results: This present study analyzed a total of 6 selected studies (1374 patients). The sensitivity and specificity of PET-CT were 0.84 (95\% confidence interval $[\mathrm{CI}]=$ 0.66 to 0.93$)$, and $0.98(95 \% \mathrm{CI}=0.97$ to 0.98$)$. Area under the curve was $0.98(95 \%$ $\mathrm{CI}=0.96$ to 0.99 ).

Methods: Studies were systematically searched for relevant PET-CT original articles in the MEDLINE and EMBASE databases. We calculated the pooled sensitivity, specificity, and likelihood ratios for ${ }^{18} \mathrm{FDG}$ PET-CT. We also constructed the summary receiver-operating characteristic curve for ${ }^{18}$ FDG PET-CT.

Conclusions: ${ }^{18}$ FDG PET-CT has high sensitivity and specificity for the detection of second primary cancers in cancer patients.

\section{INTRODUCTION}

The emergence of second primary cancers (SPCs) is one of the important prognostic factors in cancer patients. SPCs are the leading cause of treatment failure and death in cancer patients with early-stage disease. The early detection of SPCs is essential to reduce the mortality associated with SPCs, particularly in patients without the symptoms that are indicative of a SPC.

Conventional imaging modalities such as simple radiography and computed tomography are not suitable for the detection of SPCs because of the relatively low sensitivity and limited field of coverage [1-4]. Integrated positron emission tomography-computed tomography (PET-CT) could provide more anatomical details for the PET images, which may provide new insights for screening SPCs. Although some studies have reported the use of ${ }^{18}$ FDG PET-CT for the detection of SPCs, the accuracy of PET-CT remains to be controversial [1-6]. Here, we performed a meta-analysis to evaluate the accuracy of ${ }^{18} \mathrm{FDG}$ PET-CT for the detection of SPCs in cancer patients at staging.

\section{RESULTS}

Literature identification

The electronic search yielded 56 articles; 43 articles were excluded by reading the abstract because they did not present any diagnostic information. We screened in 13 full-text articles and rejected 7 full-text articles. 6 articles [1-6] were eligible for meta-analysis (Figure 1). Four 
$(66.7 \%)$ of the 6 studies stated that they were prospective. The clinical and imaging characteristics of all six included studies were shown in Table 1. A total of six studies (1350 patients) were analyzed for the accuracy of ${ }^{18}$ FDG PET-CT for the detection of SPCs, including 501 head and neck cancer patients with, 472 esophageal cancer patients, 277 lung cancer patients, 13 gastric cancer patients, and 87 patients with other subtypes of cancer. Of all six studies, 93.6\% (1263/1350) of the first primary cancers are carcinomas of the upper aerodigestive tract. In five of all six studies [1-5], the results of ${ }^{18}$ FDG PET-CT was stated to have been assessed in a qualitative manner. And there was still one study [6] in which the assessing manner was both quantitative and qualitative.

\section{Study quality}

The results of quality assessment for all six studies was shown in Table 2. For only one study [1], the item of patient selection (risk of bias and applicability concerns) was assessed as low-risk. For all six studies [1-6], the results of ${ }^{18} \mathrm{FDG}$ PET/PET-CT were interpreted without any knowledge of the gold standard. But the gold standard wasn't executed without any knowledge of the results of ${ }^{18}$ FDG PET/PET-CT in all six studies [1-6].

\section{Diagnostic accuracy of ${ }^{18}$ FDG PET-CT}

Figure 2 shows the forest plot of sensitivity and specificity for ${ }^{18}$ FDG PET-CT in the detection of SPCs. When considering all 6 studies (1350 patients) [1-6], the pooled sensitivity, specificity, positive likelihood ratio (PLR), and negative likelihood ratio (NLR) with 95\% confidence interval for PET-CT were $0.84(0.66-0.93)$, 0.98 (0.97 - 0.99), 35.8 (24.2 - 53.2), and 0.16 (0.07 - 0.38), respectively. When considering 4 studies about head and neck cancer (444 patients) [3-6], the pooled sensitivity, specificity, PLR, and NLR with 95\% confidence interval for PET-CT were 0.80 (0.41 to 0.96$), 0.97$ (0.94 to 0.98 ), 25.3 (13.7 - 46.5), and 0.20 (-0.05 - 0.84), respectively.

Figure 3 shows the SROC curve for ${ }^{18} \mathrm{FDG}$ PET-CT in the detection of SPCs. The results showed that overall weighted area under the curve with 95\% confidence interval was $0.98(0.96-0.99)$.

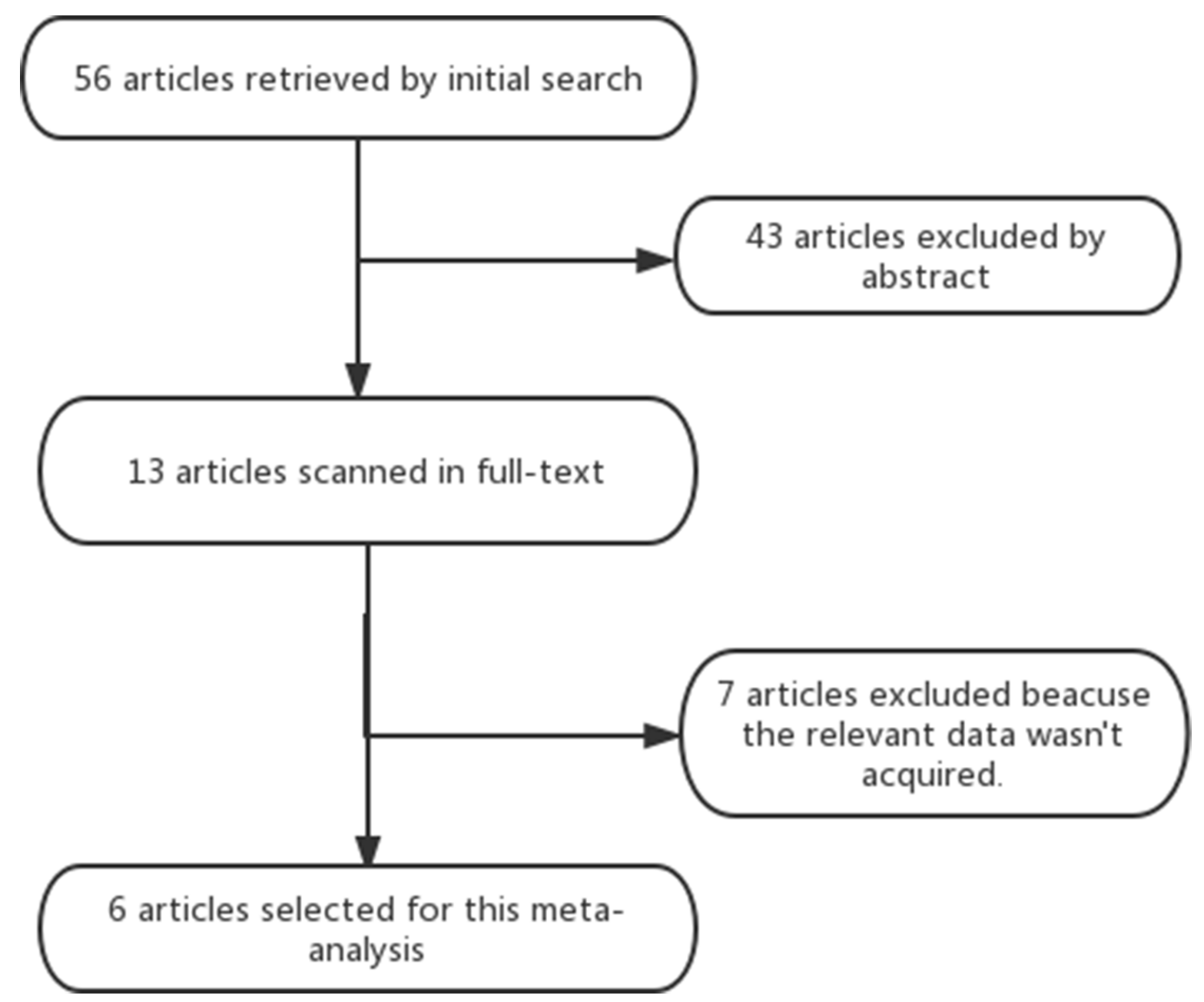

Figure 1: shows the flow chart of the search for eligible studies. 
Table 1: The clinical and imaging characteristics of all six included studies

\begin{tabular}{|c|c|c|c|c|c|c|c|c|c|c|c|}
\hline \multirow[b]{2}{*}{ Author } & \multirow[b]{2}{*}{ Year } & \multirow[b]{2}{*}{ Origin } & \multirow{2}{*}{$\begin{array}{l}\text { No. of } \\
\text { Patients }\end{array}$} & \multirow[b]{2}{*}{ Design } & \multirow{2}{*}{$\begin{array}{l}\text { Locations of the } \\
\text { first cancer }\end{array}$} & \multirow[b]{2}{*}{$\operatorname{Age}(y)$} & \multicolumn{3}{|c|}{ PET-CT Technique } & \multirow{2}{*}{$\begin{array}{l}\text { Follow-up } \\
\text { time (month) }\end{array}$} & \multirow{2}{*}{$\begin{array}{l}\text { Locations of secondary } \\
\text { primary cancer }\end{array}$} \\
\hline & & & & & & & Dose & CE-CT & $\begin{array}{l}\text { Imaging } \\
\text { interpretation }\end{array}$ & & \\
\hline Choi JW(1) & 2005 & Korea & 547 & Prospective & $\begin{array}{l}\text { Lung (277), } \\
\text { Esophagus (113), } \\
\text { Head and Neck (57), } \\
\text { Stomach (13), } \\
\text { Others (87) }\end{array}$ & 60.5 (mean) & $370 \mathrm{MBq}$ & No & qualitative & $9.2 \pm 5.2$ & $\begin{array}{l}\text { Lung (5), Esophagus (2), } \\
\text { Head and Neck (10), } \\
\text { Stomach (5), Colorectium (3), } \\
\text { Gallbladder (1). }\end{array}$ \\
\hline Chen SH(2) & 2013 & Taiwan & 359 & Retrospective & Esophagus(359) & $\begin{array}{l}30-80: 348 \\
>80: 11\end{array}$ & $370 \mathrm{MBq}$ & No & qualitative & $\begin{array}{c}\text { Not } \\
\text { Reported }\end{array}$ & $\begin{array}{l}\text { Head and Neck (10), } \\
\text { Colorectium (2), } \\
\text { Liver (1), Kidney (1) }\end{array}$ \\
\hline Hoshikawa H(5) & 2013 & Japan & 88 & Prospective & Head and Neck(88) & $40-83$ & $3.5 \mathrm{MBq} / \mathrm{kg}$ & No & qualitative & $\geq 6$ & $\begin{array}{l}\text { Lung (1), Esophagus (1), } \\
\text { Colorectium (2), Pancreas (1) }\end{array}$ \\
\hline Kim JW(3) & 2013 & Korea & 119 & Prospective & Head and Neck(119) & $20-83$ & $370-555 \mathrm{MBq}$ & No & qualitative & $\geq 18$ & $\begin{array}{l}\text { Lung (1), Esophagus (1), } \\
\text { Head and Neck (2), } \\
\text { Prostate (1) }\end{array}$ \\
\hline Seepage Y(4) & 2013 & Japan & 170 & Retrospective & Head and Neck(170) & $30-89$ & $222-333 \mathrm{MBq}$ & No & qualitative & $\geq 12$ & $\begin{array}{l}\text { Lung (7), Esophagus (1), Head } \\
\text { and Neck (1), } \\
\text { Stomach (1), Prostate (1) } \\
\text { Colorectium (2), Liver (1) } \\
\text { Breast (1), lymphoma (1) }\end{array}$ \\
\hline Park MJ(6) & 2017 & Korea & 67 & Prospective & Head and Neck(67) & $49-64$ & $370-555 \mathrm{MBq}$ & No & $\begin{array}{l}\text { Both qualitative } \\
\text { and quantitative }\end{array}$ & $\geq 18.3$ & $\begin{array}{l}\text { Head and Neck (1), } \\
\text { Prostate (1) }\end{array}$ \\
\hline
\end{tabular}

Table 2: QUADAS-2 results for all six included studies

\begin{tabular}{|c|c|c|c|c|c|c|c|}
\hline \multirow[b]{2}{*}{ Studies } & \multicolumn{4}{|c|}{ Risk of bias } & \multicolumn{3}{|c|}{ Applicability concerns } \\
\hline & $\begin{array}{c}\text { Patient } \\
\text { selection }\end{array}$ & $\begin{array}{c}\text { Index } \\
\text { test }\end{array}$ & $\begin{array}{c}\text { Reference } \\
\text { standard }\end{array}$ & $\begin{array}{c}\text { Flow and } \\
\text { timing }\end{array}$ & $\begin{array}{c}\text { Patient } \\
\text { selection }\end{array}$ & $\begin{array}{c}\text { Index } \\
\text { test }\end{array}$ & Reference standard \\
\hline Choi JW(1) & - & - & + & - & - & - & - \\
\hline Chen SH(2) & + & - & + & - & + & - & - \\
\hline $\begin{array}{l}\text { Hoshikawa } \\
\mathrm{H}(5)\end{array}$ & + & - & + & - & + & - & - \\
\hline Kim JW(3) & + & - & + & - & + & - & - \\
\hline Seepage Y(4) & + & - & + & - & + & - & - \\
\hline Park MJ(6) & + & _- & + & _ & + & _- & _- \\
\hline
\end{tabular}

When the prevalences of SPCs in cancer patients were assumed to be $5 \%, 10 \%$, and $15 \%$, the negative predictive values for ${ }^{18} \mathrm{FDG}$ PET-CT were $0.99,0.98$, and 0.97 , respectively.

\section{DISCUSSION}

The malignancies of the upper aerodigestive tract (oral cancer, pharyngeal cancer, laryngeal cancer, esophageal cancer, gastric cancer, and lung cancer, etc.) have an increased risk of SPCs, which has an incidence of 5\% to $10 \%$ [1-8]. The most well-known sites for SPCs are also aerodigestive tract organs, such as the oral cavity, pharynx, larynx esophagus, stomach and lung [1-8]. The early detection of SPCs is crucial for choosing the most effective management strategies.

Conventional imaging modalities had limited field of coverage and the relatively low sensitivity for detecting SPCs. Conventional imaging modalities on their own can miss early lesions of SPCs due to normal variation and the mobility of body structures [1]. Integrated PET-CT can provide both the metabolic and anatomic information of a cancer. In the previous study, ${ }^{18}$ FDG PET-CT showed a high sensitivity of $88.5 \%$ (23 of 26 patients) in detecting SPCs, which was significantly higher than the $61.5 \%$ (16 of 26) from a conventional staging work-up. In this metaanalysis, 6 studies about the clinical use of PET-CT for screening SPCs (1350 patients) were included. And the 

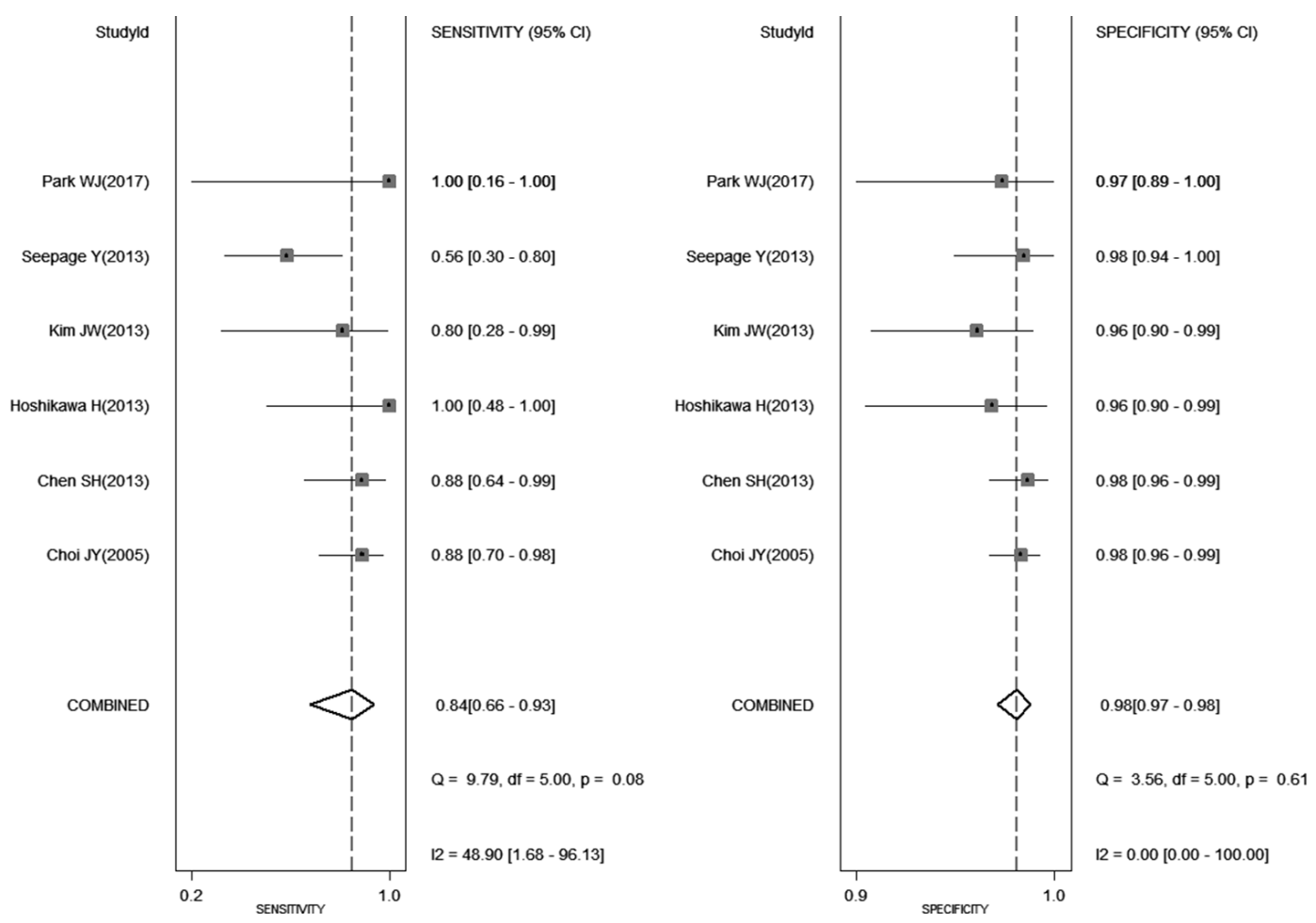

Figure 2: shows the forest plot of sensitivity and specificity for ${ }^{18}$ FDG PET-CT in the detection of second primary cancers.

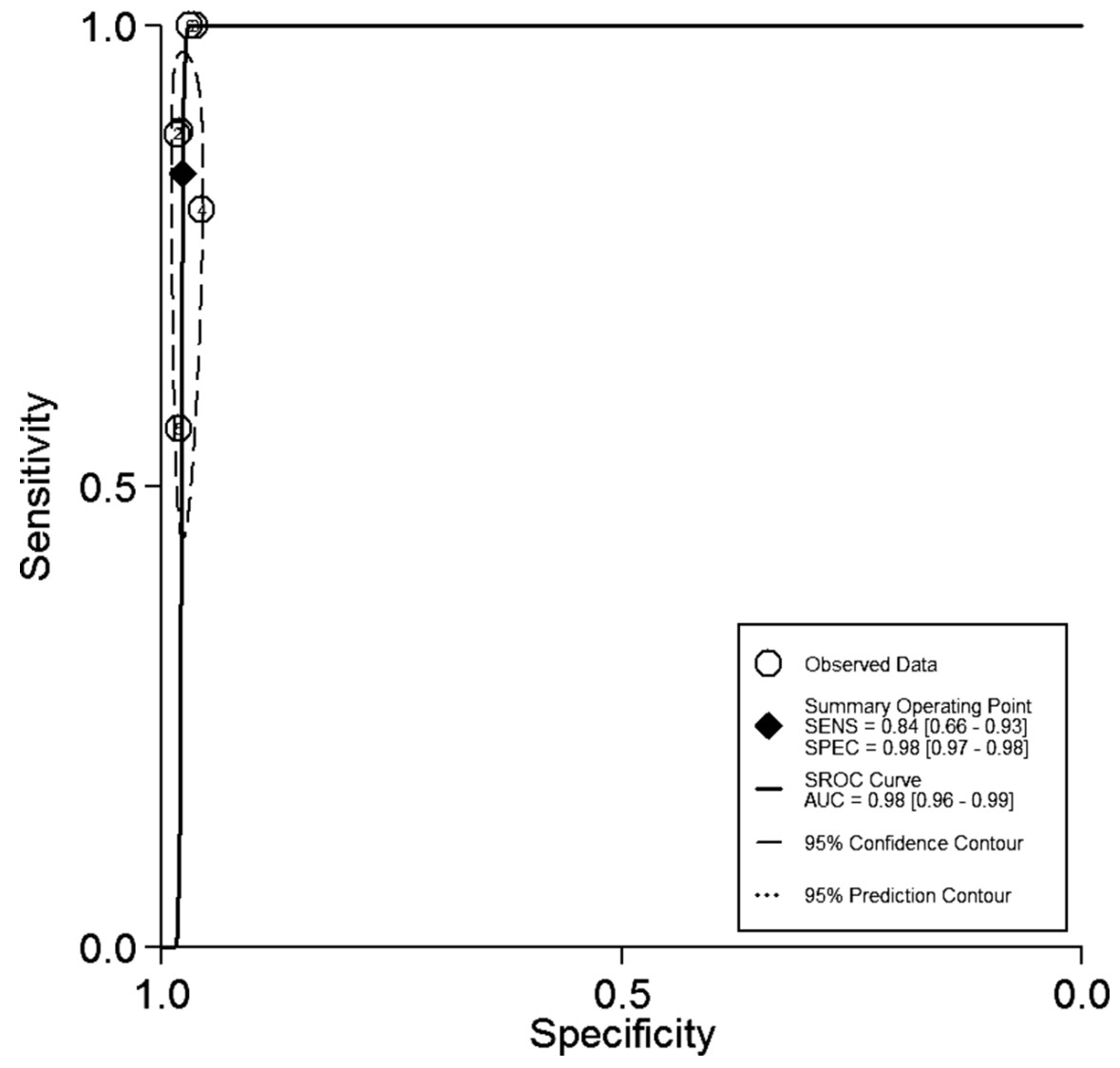

Figure 3: shows the SROC curve for ${ }^{18}$ FDG PET-CT in the detection of second primary cancers. 
weighted overall estimates of sensitivity and specificity for PET-CT were 0.84 (95\% CI $=0.66$ to 0.93$)$ and 0.98 $(95 \% \mathrm{CI}=0.97$ to 0.99$)$. This meta-analysis showed that PET-CT can be used as an effective diagnostic tool for detection of second primary cancers. An additional PETCT is essential for ruling out the presence of SPCs when abnormal findings of conventional imaging modalities are indicative of SPCs. But ${ }^{18}$ FDG PET-CT has a lower sensitivity for screening early-stage carcinomas of digestive tract (esophageal cancer, gastric cancer, intestinal cancer, and colorectal cancer [1-6].

The negative predictive value is a single indicator of diagnostic test about the probability that a patient does not have SPCs when the results of PET-CT are negative. This meta-analysis showed that the negative predictive values for ${ }^{18}$ FDG PET-CT were 0.99, 0.98, and 0.97 when the prevalences of SPCs in cancer patients were assumed to be $5 \%, 10 \%$, and $15 \%$. When the prevalence of SPCs in cancer patients were assumed to be $5-15 \%,{ }^{18} \mathrm{FDG}$ PET-CT is very informative lowering the probability of disease to as low as $1-3 \%$ when the results of PET-CT are negative.

There were several limitations in this meta-analysis. First, not all included studies had a prospective design. The retrospective studies may have some inevitable limitations. For example, the imaging interpreters may have known some results of conventional imaging before interpreting PET-CT. Second, the publication bias from positive results is a major concern because of the discarded tendency of studies with nonsignificant results. The funnel plot of this meta-analysis was not performed because the number of included studies is only six. Third, there was no single imaging strategy for the follow-up of SPCs in all six studies, which may have affected the accurate evaluation of PET-CT. Fourth, 93.6\% of the first primary cancers in this meta-analysis are carcinomas of the upper aerodigestive tract. The accuracy of ${ }^{18}$ FDG PET-CT from this meta-analysis can be applied only to carcinomas of the upper aerodigestive tract.

In conclusion, ${ }^{18}$ FDG PET-CT has high sensitivity and specificity for screening SPCs in cancer patients. Further large and prospective studies are needed to evaluate the value of PET-CT for the detection of SPCs sites in patients with other subtypes of cancer.

\section{MATERIALS AND METHODS}

\section{Literature search}

Two reviewers (LY and $\mathrm{MJ}$ ) independently undertook a computer-aided search of the MEDLINE and EMBASE databases to identify relevant studies (last update July 30, 2017), with the following combination of search terms: second primary cancers, synchronous cancers, secondary cancers, PET, positron emission tomography. The reference lists of all included studies were also screened for potentially eligible studies.
Authors of eligible studies were also contacted for supplementing additional data if the key information was missing.

\section{Study selection}

PET-CT studies that met the following criteria were included: (a) ${ }^{18}$ FDG PET-CT was used to detect all subtypes of SPCs in cancer patients. Studies about ${ }^{18}$ FDG PET-CT for the detection of the specific subtype of second primary cancers were excluded. (b) the studies were based on per-patient statistics; (c) totals of true-positives, false-positives, true-negatives, and false-negatives were provided or could be calculated; (d) histopathologic data and/or results of imaging follow-up served as the gold standard; (e) the selected studies included at least 20 patients. (f) When data were presented in more than one article, the article with the most details was chosen. (g) non-original articles (letters, abstracts, interviews, case report, editorials, and comments) were excluded in this meta-analysis.

\section{Data extraction}

Two reviewers (LY and MJ) independently extracted the data from each study, including the first author, time of publication, patient age (mean or median), number of patients included, study design (prospective or retrospective), technical characteristics and interpretation method of PET-CT, execution of the gold standard, and study results (totals of true positives, false positives, true negatives, and false negatives). Two reviewers (LY and $\mathrm{MJ})$ resolved any difference by consensus. To calculate the sensitivity and specificity, a true positive result was considered when PET-CT suggested a SPC that could be confirmed subsequently, whereas a result was considered false positive when a SPC could not be confirmed. A true negative result was considered when no SPC was detected by other imaging modalities during follow-up period. The result was classified as false negative if a SPC was detected by other diagnostic modalities after a negative result of PET-CT.

\section{Quality assessment}

Two reviewers (LY and MJ) independently evaluated the methodological quality of all six included studies using the updated quality assessment tool "Quality Assessment of Diagnostic Accuracy Studies (QUADAS)-2” [9].

\section{Statistical analysis}

We carried out all statistical analyses by Stata 12.0 (Stata Corporation, College Station, TX). We used the bivariate model to obtain weighted overall estimates of diagnostic performance (i.e., sensitivity, specificity, PLR and NLR) as the main outcome measures, and to 
construct summary receiver operating characteristic (SROC) curves for ${ }^{18}$ FDG PET-CT $[10,11]$. We used the summary estimates of sensitivity and specificity for PETCT obtained in the meta-analysis to calculate the NPVs for PET-CT when the prevalences of SPCs in cancer patients were assumed to be $5 \%, 10 \%$, and $15 \%$.

\section{ACKNOWLEDGMENTS}

No external found was received in this study.

\section{CONFLICTS OF INTEREST}

The authors declare no conflicts of interest.

\section{REFERENCES}

1. Choi JY, Lee KS, Kwon OJ, Shim YM, Baek CH, Park K, Lee KH, Kim BT. Improved detection of second primary cancer using integrated [18F] fluorodeoxyglucosepositron emission tomography and computed tomography for initial tumor staging. J Clin Oncol. 2005; 23:7654-7659

2. Chen SH, Chan SC, Chao YK, Ye TC. Detection of synchronous cancers by fluorodeoxyglucose positron emissiontomography/computed tomography during primary staging workup for esophag-eal squamouscell carcinoma in Taiwan. PLoS One. 2013; 29, 8:e82812.

3. Kim JW, Roh JL, Kim JS, Lee JH, Cho KJ, Choi SH, Nam SY, Kim SY. (18)F-FDG PET/CT surveillance at 3-6 and 12 months for detection of recurrence and second primary cancer in patients with head and neck squamous cell carcinoma. Br J Cancer. 2013; 109:2973-2979.

4. Suenaga Y, Kitajima K, Ishihara T, Sasaki R, Otsuki N, Nibu K, Minamikawa T, Kiyota N, Sugimura K. FDG-PET/ contrast-enhanced CT as a post-treatment tool in head and neck squamous cell carcinoma: comparison with FDG-PET/ non-contrast-enhanced CT and contrast-enhanced CT. Eur Radiol. 2016; 26:1018-1030.

5. Hoshikawa H, Kishino T, Mori T, Nishiyama Y, Yamamoto Y, Mori N. The value of 18F-FLT PET for detecting second primary cancers and distant metastases in head and neck cancer patients. Clin Nucl Med. 2013; 38:e318-23.

6. Park MJ, Oh JS, Roh JL, Kim JS, Lee JH, Nam SY, Kim SY. ${ }^{18} \mathrm{~F}$-FDG PET/CT versus contrast-enhanced CT for staging and prognostic prediction in patients with salivary gland carcinomas. Clin Nucl Med. 2017; 42:e149-156.

7. Lee JS, Ahn JY, Choi KD, Song HJ, Kim YH, Lee GH, Jung HY, Ryu JS, Kim SB, Kim JH, Park SI, Cho KJ, Kim JH. Synchronous second primary cancers in patients with squamous esophageal cancer: clinical features and survival outcome. Korean J Intern Med. 2016; 31:253-259.

8. Bold B, Piao Y, Murata Y, Kishino M, Shibuya H. Usefulness of PET/CT for detecting a second primary cancer after treatment for squamous cell carcinoma of the head and neck. Clin Nucl Med. 2008; 33:831-833.

9. Whiting PF, Rutjes AW, Westwood ME, Mallett S, Deeks JJ, Reitsma JB, Leeflang MM, Sterne JA, Bossuyt PM; QUADAS-2 Group. QUADAS-2: a revised tool for the quality assessment of diagnostic accuracy studies. Ann Intern Med. 2011; 155:529-536

10. Chu H, Cole SR. Bivariate meta-analysis of sensitivity and specificity with sparse data: a general linear mixed model approach. J Clin Epidemiol. 2006; 59:1331-1332.

11. Reitsma JB, Glas AS, Rutjes AW, Scholten RJ, Bossuyt PM, Zwinderman AH. Bivariate analysis of sensitivity and specificity produces informative summary measures in diagnostic reviews. J Clin Epidemiol. 2005; 58:982-990. 